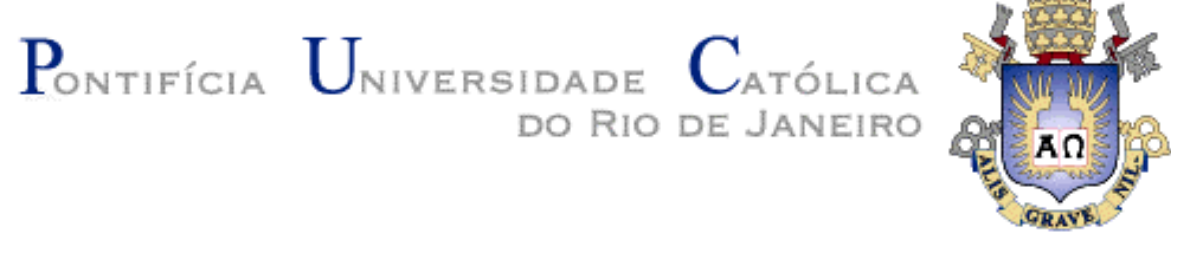

Eudes Siqueira Muniz

\title{
Desenvolvimento de equipamento e metodologia de testes para avaliação da interação folhelho-fluido de perfuração
}

TESE DE Doutorado

DEPARTAMENTO DE ENGENHARIA CIVIL

Programa de Pós-graduação em Engenharia Civil 


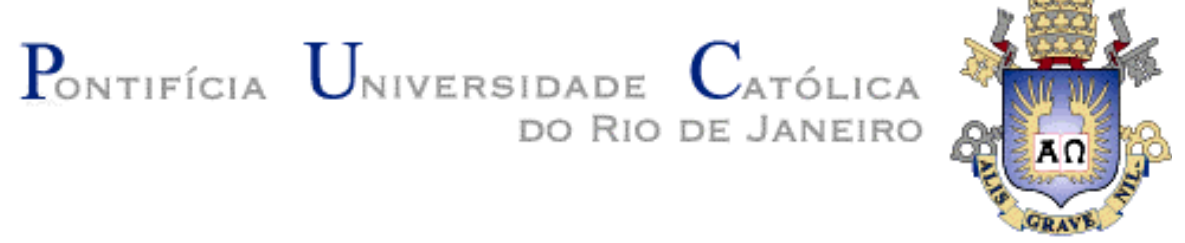

Eudes Siqueira Muniz

Desenvolvimento de equipamento e metodologia de testes para avaliação da interação folhelho-fluido de perfuração

Tese de Doutorado

Tese apresentada ao Programa de Pós-graduação em Engenharia Civil da PUC-Rio como requisito parcial para obtenção do título de Doutor em Engenharia Civil. Área de concentração: Geotecnia.

Orientador: Sérgio A. B. da Fontoura

Rio de Janeiro

Junho de 2003 


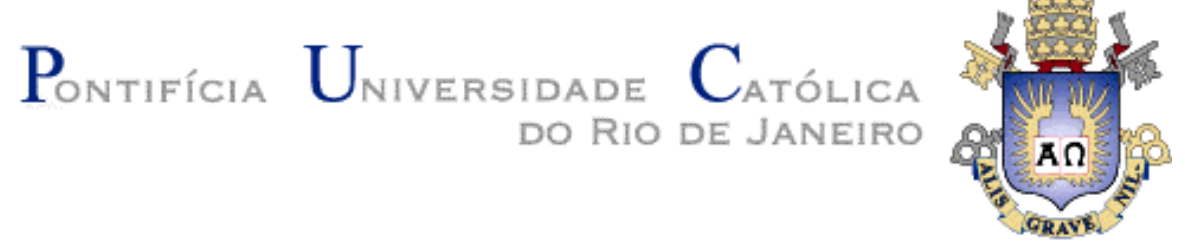

Eudes Siqueira Muniz

\title{
Desenvolvimento de Equipamento e Metodologia de Testes para Avaliação da Interação Folhelho-Fluido de Perfuração
}

\begin{abstract}
Tese apresentada ao Programa de Pós-graduação em Engenharia Civil da PUC-Rio como requisito parcial para obtenção do título de Doutor em Engenharia Civil. Aprovada pela Comissão Examinadora abaixo assinada.
\end{abstract}

Sérgio A. B. da Fontoura

Orientador

Departamento de Engenharia Civil - PUC-Rio

Dr. Mauro Bloch

CENPES/ Petrobras

Dra. Rosana Fátima T. Lomba

CENPES/ Petrobras

Prof. Alberto de Sampaio F. J. Sayão

Departamento de Engenharia Civil - PUC-Rio

Prof. Tácio Mauro P. de Campos

Departamento de Engenharia Civil - PUC-Rio

Prof. Ney Augusto Dumont

Coordenador Setorial do Centro

Técnico Científico - PUC-Rio

Rio de Janeiro, 04 de Junho de 2003 
Todos os direitos reservados. É proibida a reprodução total ou parcial do trabalho sem autorização da universidade, do autor e do orientador.

\section{Eudes Siqueira Muniz}

Graduou-se em Engenharia de Minas na UFOP (Universidade Federal de Ouro Preto) em 1995. Em 1998 defendeu a dissertação de mestrado intitulada "Nova Metodologia de Ensaios Triaxiais de Folhelhos" junto ao Departamento de Engenharia Civil da PUC-Rio. Desde então vem se dedicando ao estudo dos problemas de instabilidade em poços de petróleo provocados por interações fisico-químicas entre o fluido de perfuração e a rocha perfurada.

Muniz, Eudes Siqueira

Desenvolvimento de equipamento e metodologia de testes para avaliação da interação folhelho-fluido de perfuração / Eudes Siqueira Muniz; orientador: Sérgio Augusto B. da Fontoura. - Rio de Janeiro: PUC, Departamento de Engenharia Civil, 2003.

[18]. , 175 f. : il. ; $30 \mathrm{~cm}$

Tese (doutorado) - Pontifícia Universidade Católica do Rio de Janeiro, Departamento de Engenharia Civil.

Inclui referências bibliográficas.

1. Engenharia Civil - Teses. 2. Folhelhos. 3. Difusão. 4. Interação rocha- fluido. 5. Estabilidade de poços de petróleo.

6. Ensaios de laboratório. I. Fontoura, Sérgio Augusto B. da. II. Pontifícia Universidade Católica do Rio de Janeiro. Departamento de Engenharia Civil. III. Título. 
A minha mãe, Ana Maria, exemplo de sabedoria e sinceridade 


\section{Agradecimentos}

Ao CNPq, ANP e à PUC-Rio, pelos auxílios concedidos, sem os quais este trabalho não poderia ter sido realizado.

Ao meu orientador Sérgio A. B. da Fontoura pela paciência, confiança e respeito profissional depositados em minha pessoa para o desenvolvimento deste trabalho.

A todos professores e funcionários do Departamento de Engenharia Civil pelos ensinamentos e total apoio no decorrer deste trabalho. Agradeço especialmente aos funcionários do Laboratório de Geotecnia, William, Sr. José, Amauri, Josué e Rosa, pela ajuda e atenção dada nestes 4 anos de pesquisa.

Aos colegas do GTEP e especialmente à equipe do Laboratório de Interação Rocha-Fluido, Fernanda Carvalho, Marcelo Malta, Caetano, Olga Cecília, Claudio Rabe, Luiz Guilherme, Ricardo e Michele, que participaram direta ou indiretamente na realização deste trabalho.

À minha tia Maria Geralda e família pelo apoio dado a meu irmão que posteriormente pode me ajudar a concluir o segundo grau.

À minha família pela atenção, carinho e incentivo em todos os momentos da minha vida. Em especial à minha esposa, Cleide Jeane, pela paciência em ouvir meus problemas e conquistas, e por me impedir de trabalhar todos os finais de semana, afinal existe vida durante a tese.

Aos colegas da PUC-Rio e aos ex-companheiros de moradia pela amizade e salutar convívio de gratas recordações.

Aos professores que participaram da Comissão Examinadora. 


\section{Resumo}

Muniz, Eudes Siqueira; Fontoura, Sérgio Augusto B. Desenvolvimento de equipamento e metodologia de testes para avaliação da interação folhelho-fluido de perfuração. Rio de Janeiro, 2003. 175 p. Tese de Doutorado - Departamento de Engenharia Civil, Pontifícia Universidade Católica do Rio de Janeiro.

A perfuração de poços de petróleo através de folhelhos, que se constituem na maioria das rochas da coluna estratigráfica, pode apresentar problemas de instabilidade devido às interações físico-químicas entre os fluidos de perfuração e estas rochas. Os custos associados à solução destes problemas são muito altos e dependendo da intensidade destes problemas, poços podem ser perdidos.

Nesta tese, um novo equipamento, capaz de reaplicar parte das tensões que estão atuando na amostra de rocha, foi desenvolvido. Uma metodologia de testes para avaliar os mecanismos de interação rocha-fluido e para determinar os parâmetros de transporte de massa, necessários para análises de estabilidade de poços, é proposta. Especificamente, parâmetros que descrevem o transporte de água e íons devido a gradientes hidráulicos e químicos são determinados. O conhecimento destes parâmetros contribui para compreender a eficiência do fluido de perfuração no controle de instabilidades durante a perfuração.

Testes realizados em dois folhelhos de plataformas "offshore" usando diferentes fluidos demonstraram a eficiência do equipamento e da metodologia de testes. Os parâmetros de transporte obtidos são consistentes com valores obtidos em outros trabalhos.

\section{Palavras-chave}

Folhelhos; Interação rocha-fluido; Estabilidade de poços de petróleo; Difusão; Ensaios de laboratório. 


\section{Abstract}

Muniz, Eudes Siqueira; Fontoura, Sérgio Augusto B. (Advisor). Development of Equipment and Testing Methodology to Evaluate Rock-Drilling Fluid Interaction. Rio de Janeiro, 2003, 175 p. DSc. Thesis. Department of Civil Engineering, Pontifícia Universidade Católica do Rio de Janeiro.

The drilling of oil wells through shales, which constitute the majority of rocks in the stratigraphic column, may present instability problems due to physico-chemicals interactions between the drilling fluids and these rocks. The costs associated to the solution of these problems are very high and, depending upon the intensity of these problems, wells can be lost.

In this thesis, a new equipment was developed which is capable of reapplying part of the stresses that were acting upon the rock sample. A testing methodology to evaluate rock-fluid interaction mechanisms and to determine the mass transport parameters, needed for wellbore stability analyses, is proposed. Specifically, parameters that describe the transport of water and ions due to hydraulic and chemicals gradients are determined. The knowledge about these parameters is instrumental to understand the efficiency of the drilling fluid in controlling instabilities during drilling.

Tests carried out in two shales from offshore platforms using different fluids demonstrated the efficiency of equipment and of the testing methodology. The transport parameters obtained are consistent with values obtained elsewhere.

\section{Keywords}

Shales; rock-fluid interactions; wellbore stability; diffusion; Laboratory tests. 


\section{Sumário}

\section{Introdução}

1.1. Motivação

1.2. Objetivo 20

1.3. Escopo 20

\section{Revisão Bibliográfica}

2.1. Considerações Gerais 22

2.1.1. Enceramento de Brocas ou "Bit-Balling" 22

2.1.2. Dispersão de Cascalhos 23

2.1.3. Rupturas por Compressão ou Tração 23

2.2. Estudos nesta Linha de Pesquisa 24

2.2.1. Equipamentos e Resultados Apresentados na Literatura 29

2.3. Considerações Finais 41

3 Desenvolvimento do Equipamento e da Metodologia de Ensaios

3.1. Introdução 43

3.2. Fase I (Outubro 1998 - Janeiro 1999) 43

3.2.1. Ensaios Realizados 45

3.3. Fase II (Fevereiro 1999 - Dezembro 1999) 48

3.3.1. Ensaios Preliminares $\quad 49$

3.3.2. Ensaios em Folhelhos $\quad 51$

3.3.3. Conclusões 53

3.4. Fase III - (Janeiro 2000 - Outubro 2000) 53

3.4.1. Ensaios de Difusão por Gradiente Hidráulico 55

3.4.2. Conclusões $\quad 57$

3.5. Fase IV - (Outubro 2000 - Junho 2001) 58

3.5.1. Ensaio de Difusão em Folhelho - CP26 59

3.5.2. Conclusões 63

3.6. Fase V - (Junho 2001 - Novembro 2001) 63

3.6.1. Ensaios em Folhelhos $\quad 64$

3.6.1.1. Ensaio no Corpo de Prova 27

3.6.1.2. Ensaio no Corpo de Prova $28 \quad 68$

3.6.1.3. Ensaio no Corpo de Prova $29 \quad 71$

3.6.1.4. Ensaio no Corpo de Prova $14 \quad 74$

3.6.2. Ensaios em Membrana Osmótica $\quad 75$

3.7. Conclusões $\quad 79$ 


\section{Metodologia de Ensaios e Análises}

4.1. Comentários Gerais $\quad 80$

4.2. Preparação do Sistema 80

4.3. Etapa de Preparação do Corpo de Prova 83

4.4. Etapa de Saturação do Corpo de Prova 84

4.5. Etapa de Consolidação do Corpo de Prova 88

4.6. Etapa de Difusão de Pressão do Corpo de Prova 88

4.7. Etapa de Difusão de Íons do Corpo de Prova 89

4.8. Análise dos Resultados Utilizando o Programa Fporo 91

4.9. Conclusões $\quad 93$

\section{Medidas de Concentração}

5.1. Comentários Gerais $\quad 95$

5.2. Medidas de Concentração Utilizando o Condutivímetro 96

5.2.1. Equipamento e Metodologia Utilizada 96

5.2.2. Ensaios de Calibração $\quad 97$

5.3. Medidas de Concentração Utilizando a Fibra Óptica 98

5.3.1. Equipamento e Metodologia Utilizada 98

5.3.2. Ensaios de Calibração 100

5.4. Ensaios Realizados 104

5.4.1. Ensaios com Cloreto de Cálcio $\left(\mathrm{CaCl}_{2}\right) \quad 104$

5.4.2. Ensaio com Formiato de Sódio (NaCOOH) 111

5.5. Reavaliação da Fibra Óptica e do Condutivímetro 115

5.6. Conclusões 122

6 Resultados e Análises

6.1. Comentários Gerais 123

6.2. Descrição dos Folhelhos Estudados 123

6.3. Ensaios de Bancada ou Sorção 127

6.3.1. Metodologia do Ensaio 128

6.3.2. Análise dos Resultados 129

6.4. Ensaios em Folhelhos na Célula de Difusão 135

6.4.1. Dados Iniciais dos Corpos de Prova 135

6.4.2. Fase de Saturação 138

6.4.3. Fase de Adensamento 141

6.4.4. Fase de Difusão de Pressão 142

6.4.5. Fase de Difusão de ĺons 150

6.4.5.1. Análise do Coeficiente de Reflexão (Eficiência de Membrana) 158

6.4.6. Análises Após a Retirada do Corpo de Prova 160

6.4.6.1. Análise do Corpo de Prova 160 
7 Conclusões e Sugestões para Trabalhos Futuros

7.1. Conclusões

166

7.2. Sugestões para Trabalhos Futuros

Referências Bibliográficas 


\section{Lista de figuras}

Figura 2. 1 - (a) Membrana semi-permeável perfeita (b) Membrana semi-permeável imperfeita (modificado de Mikulecky, 1997) 27

Figura 2. 2 - Esquema do equipamento utilizado por Ballard et al. (1992) 30

Figura 2. 3 - Esquema do equipamento utilizado por Lomba (1998) 31

Figura 2. 4 - Esquema do equipamento utilizado por van Oort (1994) 32

Figura 2. 5 - Ensaio de transmissão de pressão para fluido base óleo (van Oort, 1994) 33

Figura 2. 6 - Esquema do equipamento de transmissão de pressão e ensaios de osmose (modificado de van Oort et al., 1996) 34

Figura 2. 7 - Ensaio de fluxo osmótico (van Oort, 1994) 35

Figura 2. 8 - Esquema da célula DSC ( modificado de Simpson \& Walker, 1995) 36

Figura 2. 9 - Célula para ensaios de potencial químico (modificado de Tan et al. 1996) 39

Figura 2. 10 - Esquema do equipamento utilizado por Ewy \& Stankovich (2002) 40

Figura 3. 1 - Esquema do Kazerímetro

Figura 3. 2 - (a) Vista do Kazerímetro e o circuito de válvulas utilizado; (b) Detalhe do

Kazerímetro com o corpo de prova devidamente preparado para o ensaio

Figura 3. 3 - Difusão de pressão em solo residual, $1^{\circ}$ estágio 45

Figura 3. 4 - Difusão de pressão em solo residual, $2^{\circ}$ estágio 46

Figura 3. 5 - Configuração do sistema utilizado para avaliar o efeito osmótico $\quad 47$

Figura 3. 6 - Fase de difusão de pressão e íons em solo residual $\quad 47$

Figura 3. 7 - Esquema do equipamento desenvolvido 48

Figura 3. 8 - (a) Célula de difusão, (b) Corpo de prova de solo residual 50

Figura 3. 9 - Difusão de pressão em solo residual - Fase II 50

Figura 3. 10 - Variação das pressões no folhelho da Noruega (N) 51

Figura 3. 11 - Variação das pressões no ensaio de difusão no folhelho do Brasil (B) 52

Figura 3. 12 - Esquema das linhas de circulação e acessórios utilizados na fase III 54

Figura 3. 13 - Variação das pressões na fase de difusão de pressão - CP09 56

Figura 3. 14 - Variação das pressões na fase de difusão de pressão - CP10 57

Figura 3. 15 - Aplicador de pressão/volume - GDS 58

Figura 3. 16 - (a) Foto da interface construída; (b) Bellofram utilizado 59

Figura 3. 17 - Corpo de prova 26 após o ensaio de difusão 60

Figura 3. 18 - Variação das pressões durante a fase de difusão de pressão - CP26 61

Figura 3. 19 - Variação das pressões durante a fase de difusão de íons - CP26 62

Figura 3. 20 - (a) - Detalhe das molas feitas com os tubos de aço inoxidável (b) -

Detalhe da nova configuração com engates rápidos $\quad 65$

Figura 3. 21 - Retirada do CP27 da célula de difusão 66

Figura 3. 22 - Variação das pressões durante a fase de difusão de pressão - CP27 67 
Figura 3. 23 - Variação das pressões e deslocamento desde o início da fase de difusão de pressão-CP27 68

Figura 3. 24 - Detalhe do novo "cap" maciço e das pedras porosas de plástico 69

Figura 3. 25 - Variação da pressão axial com a temperatura 70

Figura 3. 26 - Variação das pressões desde a fase de difusão de pressão - CP28 71

Figura 3. 27 - Variação das pressões e força axial na fase de saturação (CP29) 72

Figura 3. 28 - Variação das pressões nas fases de difusão de pressão e íons - CP29 74

Figura 3. 29 - Variação das pressões nas fases de difusão de pressão e íons (CP14) 75

Figura 3. 30 - Bexiga de celofane presa à pipeta 76

Figura 3. 31 - A) Bexiga de celofane após a imersão B) 25 minutos após a imersão 76

Figura 3. 32 - Corpo de prova de celofane utilizado nos ensaios 77

Figura 3. 33 - Ensaio de difusão no corpo de prova de celofane 78

Figura 3. 34- Fase de difusão de íons do corpo de prova de celofane 79

Figura 4. 1 - Circuito de contrapressão $\quad 82$

Figura 4. 2 - Circuito de pressão confinante e axial $\quad 82$

Figura 4. 3 - Fotos da etapa de preparação do corpo de prova 85

Figura 4. 4 - Malha de elementos finitos utilizada nas análises (CP34) 92

Figura 5. 1 - (a) Leitora de dados eletroquímicos e (b) Sondas utilizadas. 96

Figura 5. 2 - Curva de calibração do condutivímetro para o $\mathrm{CaCl}_{2} \quad 97$

Figura 5. 3 - Curva de calibração do condutivímetro para o $\mathrm{NaCOOH} 98$

Figura 5. 4 - Sistema óptico básico 98

Figura 5. 5 - Novo equipamento para medida de concentração 101

Figura 5. 6 - Novo sensor utilizado no reservatório inferior 102

Figura 5. 7 - Variação do índice de refração com a concentração de $\mathrm{CaCl}_{2} \quad 103$

Figura 5. 8 - Variação do índice de refração com a concentração de $\mathrm{NaCOOH} 103$

Figura 5. 9 - Variação da concentração de sais no reservatório inferior (CP32) 104

Figura 5. 10 - Esquema do equipamento utilizado no ensaio de difusão em solo residual

Figura 5. 11 - Variação da concentração de sais no ensaio com solo residual 106

Figura 5. 12 - Variação da concentração de sais no ensaio com alumínio vazado 107

Figura 5. 13 - Variação da concentração de sais no reservatório inferior (CP33) 108

Figura 5. 14 - Tubos plásticos com o folhelho em suspensão 109

Figura 5. 15 - Tubos plásticos com o folhelho após a centrifugação 109

Figura 5. 16 - Variação da concentração ao longo do ensaio (CP35) 111

Figura 5. 17 - Variação da concentração ao longo do ensaio (CP34) 112

Figura 5. 18 - Variação da razão dos sinais da fibra óptica em função do tempo e da temperatura 
Figura 5. 19 - Variação da razão dos sinais da fibra óptica em função do tempo e da temperatura para ensaio com celofane na célula de difusão 114

Figura 5. 20 - Variação da razão (Ps/Pr) em função do tempo e da temperatura 115 Figura 5. 21 - Variação do índice de refração com a concentração para o $\mathrm{CaCl}_{2}, \mathrm{NaCl}$ e $\mathrm{KCl}$

Figura 5. 22 - Variação da condutividade com a concentração para o $\mathrm{CaCl}_{2}, \mathrm{NaCl}$ e $\mathrm{KCl}$

Figura 5. 23 - Variação da condutividade com a concentração para qualquer solução salina

Figura 5. 24 - Variação do índice de refração com a atividade para o $\mathrm{CaCl}_{2}, \mathrm{NaCl}$ e $\mathrm{KCl}$

Figura 5. 25 - Variação da condutividade com a atividade para o $\mathrm{CaCl}_{2}, \mathrm{NaCl}$ e $\mathrm{KCl} 121$ Figura 5. 26 - Variação da condutividade com a atividade para atividades maiores que 0,9

Figura 6. 1 - Lâmina delgada do folhelho N (Fontoura et al., 1999)

Figura 6. 2 - Lâmina delgada do folhelho B-S (Rabe, 2003) 126

Figura 6. 3 - Erlemmeyers fixos ao agitador magnético 128

$\begin{array}{ll}\text { Figura 6. } 4 \text { - Centrífuga para separação das fases líquida e sólida } & 128\end{array}$

Figura 6. 5 - Folhelho após a separação em centrífuga 130

Figura 6. 6 - Gráfico de Ce versus Cs para todos os pontos com um ajuste logarítmico

Figura 6. 7 - Gráfico de Ce versus Cs para Isoterma Linear 132

Figura 6.8 - Isoterma de Langmuir 133

Figura 6. 9 - Isoterma de Freundlich 134

Figura 6. 10 - Fase de saturação do CP30 138

Figura 6. 11 - Fase de saturação do CP15 140

Figura 6. 12 - Variação das pressões na fase de difusão de pressão do CP30 143

Figura 6. 13 - Variação das pressões na fase de difusão de pressão do CP31 144

Figura 6. 14 - Variação das pressões na fase de difusão de pressão do CP32 144

Figura 6. 15 - Variação das pressões na fase de difusão de pressão do CP34 145

Figura 6. 16 - Variação das pressões na fase de difusão de pressão do CP33 145

Figura 6. 17 - Variação das pressões na fase de difusão de pressão do CP37 146

Figura 6. 18 - Variação das pressões na fase de difusão de pressão do CP14 146

Figura 6. 19 - Variação das pressões na fase de difusão de pressão do CP15 147

Figura 6. 20 - Variação das pressões na fase de difusão de pressão do CP36 148

Figura 6. 21 - Variação das pressões na fase de difusão de pressão do CP38 148

Figura 6. 22 - Variação das pressões na segunda fase de difusão de pressão do CP14

Figura 6. 23 - Fase de difusão de íons do CP32 
Figura 6. 24 - Fase de difusão de íons do CP30

Figura 6. 25 - Fase de difusão de íons do CP31

Figura 6. 26 - Fase de difusão de íons do CP33

Figura 6. 27 - Fase de difusão de íons do CP37

Figura 6. 28 - Fase de difusão de íons do CP15

Figura 6. 29 - Fase de difusão de íons do CP35

Figura 6. 30 - Desenvolvimento de pressão na base para o CP31 e CP35 157

Figura 6. 31 - Fase de difusão de íons do CP34 utilizando $\mathrm{NaCOOH}$

Figura 6. 32 - Ensaio para obter a atividade química de soluções 159

Figura 6. 33 - Retirada de fluido do reservatório inferior para análise química 161 


\section{Lista de tabelas}

Tabela 2. 1 - Transporte de massa em meios porosos (modificado de Mitchel, 1993) 25

Tabela 2. 2 - Resultados obtidos no folhelho Pierre II (Tan et al. 1996)

Tabela 3. 1 - Dados iniciais do corpo de prova (CP26) 60

Tabela 3. 2 - Dados iniciais dos corpos de prova 64

Tabela 4. 1 - Faixas de trabalho de cada mola da válvula de alívio 81

Tabela 4. 2 - Parâmetros utilizados na análise numérica do CP31 93

Tabela 5. 1 - Valores de concentração obtidos para cada tubo plástico 110

Tabela 5. 2 - Valores adotados e obtidos para a calibração do $\mathrm{CaCl}_{2} \quad 116$

Tabela 5. 3 - Valores adotados e obtidos para a calibração do $\mathrm{NaCl}$

Tabela 5. 4 - Valores adotados e obtidos para a calibração do $\mathrm{KCl} \quad 117$

Tabela 6. 1 - Composição mineralógica dos folhelhos (Rabe, 2003) 124

Tabela 6. 2 - Análise semi-quantitativa dos minerais presentes nos folhelhos (Rabe, 2003) 124

Tabela 6. 3 - Concentração dos íons dissolvidos nos poros das amostras (ppm) 125

Tabela 6. 4 - Capacidade de troca catiônica do folhelho intacto (Rabe, 2003) 125

Tabela 6. 5 - Análise química das soluções 127

Tabela 6. 6 - Dados do ensaio 130

Tabela 6. 7 - Dados utilizados para traçar os gráficos de Freundlich e Langmuir 133

Tabela 6. 8 - Valores obtidos para o coeficiente de retardamento 134

Tabela 6. 9 - Dados iniciais dos corpos de prova 137

Tabela 6. 10 - Valores do parâmetro B de Skempton para os CPs 30,31 e $32 \quad 139$

Tabela 6. 11 - Valores do parâmetro B para cada corpo de prova 140

Tabela 6. 12 - Valores de permeabilidade obtido para cada corpo de prova 143

Tabela 6. 13 - Valores dos parâmetros de difusão e permeabilidade obtidos 151

Tabela 6. 14 - Coeficiente de reflexão obtido para cada CP 159

Tabela 6. 15 - Análise química do fluido presente no reservatório inferior 163 


\section{Lista de símbolos}

$a_{1}$ Atividade da água na região de menor concentração

$a_{2}$ Atividade da água na região de maior concentração

$A_{f}$ Atividade do folhelho

$A_{f p}$ Atividade do fluido de perfuração ou das soluções

A e B Parâmetros de poropressão

b Parâmetro que representa a velocidade ou energia de sorção

C Concentração

Co Concentração inicial

Ce Concentração de equilíbrio

Cs Massa sorvida por unidade de massa de sólidos secos

De Coeficiente de difusão efetivo

Dm Coeficiente de difusão molecular

e Índice de vazios

E Módulo de elasticidade

G Densidade dos grãos

H Altura do corpo de prova

K Permeabilidade

Kd Coeficiente de distribuição

Kf Módulo de compressibilidade do fluido

Ks Módulo de compressibilidade dos grãos

Kfr e $\varepsilon$ Coeficientes de Freundlich

$\mathrm{K}_{1}$ Razão de acoplamento

$\mathrm{n}_{1}$ Índice de refração do líquido

$\mathrm{n}_{2}$ Índice de refração da fibra óptica

Ms Massa de solo

Mss Massa de solo seca

Msor Massa sorvida

$P_{0} \quad$ Potência de luz emitida pelo LED

$\operatorname{Pr}$ Potência de referência

Ps Potência refletida na interface fibra-fluido

PMs Peso molecular do soluto

PMw Peso molecular do solvente

$R$ Constante universal dos gases

$\mathrm{R}_{1}$ Coeficiente de refletividade

S Grau de saturação

Sm Capacidade de sorção do solo em relação à substância de interesse

T Temperatura 
w Umidade natural

W Peso do corpo de prova

$\checkmark$ Volume do corpo de prova

$\mathrm{V}_{\mathrm{w}}$ Volume parcial molar da água

$\alpha$ Coeficiente de reflexão ou eficiência de membrana

$\alpha_{L} \quad$ Dispersividade longitudinal

$\alpha_{T}$ Dispersividade transversal

$\phi$ Porosidade

$\gamma_{T}$ Peso específico total

$\gamma_{w}$ Peso específico da água

$\tau$ Coeficiente de tortuosidade

$v$ Coeficiente de Poisson

$v_{a}$ Mobilidade da água

$v_{s}$ Mobilidade do soluto

$\rho$ Coeficiente de retardamento

$\rho_{\mathrm{s}}$ Massa específica seca do solo

$\Delta \mathrm{P}_{\text {osm }} \quad$ Pressão osmótica

$\Delta \mathrm{u}$ Variação de poropressão

$\Delta \sigma_{\text {conf }} \quad$ Variação de pressão confinante

$\Delta \sigma_{\text {axial }} \quad$ Variação de pressão axial

П Pressão osmótica teórica 